\title{
Etnoficciones del origen. Arte La representación de Los funerales de Atahualpa en un mate burilado
}

\author{
María Eugenia Yllia Miranda \\ Instituto de Investigaciones Museológicas y Artísticas / Universidad Ricado Palma
}

Este ensayo aborda las divergencias existentes entre las identidades locales e ideologías nacionales que subyacen del análisis de un mate burilado atribuido a Mariano Flores, pieza que reproduce la pintura Los Funerales de Atahualpa de Luis Montero. La incorporación de la famosa obra decimonónica en un repertorio indígena constituye una etnoficción de la nación, elaborada desde el mundo rural e iletrado y evidencia su falaz encuentro con la ciudad letrada y la cultura hegemónica.

\section{Mate burilado / arte popular / etnoficción / arte indígena / arte mestizo / intelectuales / los Funerales de Atahualpa}

This paper deals with the discrepancies between local identities and national ideologies that lie behind the analysis of a mate burilado (carved gourd) attributed to Mariano Flores. This object reproduces the painting The Funeral of Atahualpa by Luis Montero. The inclusion of this renowned nineteenth-century artwork within an indigenous repertoire is an ethnofiction of the nation, developed from rural and illiterate communities, and demonstrates their fallacious encounter with the ciudad letrada ('lettered city') and the dominant culture.

\section{Mate burilado (gourd art) / folk art / ethnofiction / indigenous art / mestizo art / intellectuality / Los Funerales de Atahualpa}

\section{Introducción}

La singularidad estética de los mates burilados procedentes de Huancavelica y Ayacucho los emplazó durante las primeras décadas del siglo XX como uno de los géneros más valorados del arte peruano. Fue reconocido tempranamente como arte indígena (Mariátegui 1927), mestizo (Sabogal 1929), o un auténtico arte nacional ${ }^{2}$. En este universo representativo la combinación de imágenes y textos -escritos en español, quechua o simultáneamente en ambos idiomas- es una de sus características más reveladoras en algunos repertorios, que con la distancia de los años, además de proporcionar información sobre el contexto

1 El arraigo milenario de su soporte, la calabaza Lagenaria vulgaris; su manufactura emparentada con técnicas de plateros españoles; la procedencia social de sus artífices; y las escenas que presentaba: históricos, académicos, citadinos, festivos y campesinos.

2 En 1920 el semanario Variedades difundió la exposición de arte ayacuchano organizada por el pintor José Otero en la Casa Protzel de Huamanga con motivo de la celebración de la batalla de Ayacucho. Además de piezas en piedra de Huamanga, platería, filigrana, imaginería, se exhibió mates burilados (Otero, 1920). El mismo medio propagó, una semana después, la foto de un "mate curiosamente labrado por un indio de Huanta representando escenas de la entrada del coronel Parra a esa ciudad después de la revolución del $1895^{\prime \prime}$ (Variedades). Intelectuales extranjeros como el mexicano Rafael Heliodoro Valle no fueron ajenos a la destreza en su ejecución (Variedades). En 1925 Elena Izcue presentó en la Exposición Panamericana de Los Ángeles la pintura El decorador de mates (Majluf y Wuffarden 1999:38). José Carlos Mariátegui exhortó a Sabogal a través de Amauta a reconocer a uno de los indios que "anónima, pero a veces genialmente decoran mates en la sierra" (Mariátegui 1927). Antonino Espinoza Saldaña compara el estilo abigarrado de Julia Codesido con "la manera como se decoran hoy los mates de nuestra serrania, imprimiendo a sus figuras, espontáneamente un sello nacional definido" (Wuffarden 2004: 16). Todos estos referentes señalan que durante los años veinte, el mate se había convertido en legítimo representante de un arte nacional. 
en que fueron realizados, permiten enriquecer y complejizar su análisis convirtiéndolos en objetos polivalentes, teniendo en cuenta que son ejecutados por sociedades orales y quechua hablantes. El carácter hispano en la composición de los temas y los elementos decorativos, producto de un proceso denominado por Sabogal (1945) como "plástico-criollo" fueron algunos de los aspectos que deslumbraron a los indigenistas, pero también la incorporación de textos en filacterias y cintas parlantes hicieron posible tener un mayor acercamiento y comprensión de sus discursos narrativos y diferenció a los mates del resto de objetos artísticos producidos por la población rural.

Esta suerte de "fetichización de la escritura" Liendhard (1990), se da en espacios donde ésta es protagónica de las realizaciones de poder y refleja-como en el caso de los mateslas consecuencias de la violencia simbólica que generó la implantación del idioma y la escritura. La diversidad de códigos que convergen en los mates, los muestran como lugares de encuentro entre grupos sociales antagónicos y diversos: las sociedades indígenas y las élites mestizas, criollas e ilustradas.

En este gran corpus de objetos hay una pieza que destaca por el discurso que subyace en los repertorios que ostenta. Se trata del azucarero que cita la pintura "Los Funerales de Atahualpa" de Luis Montero (Florencia 1861-1867), que lleva escrito el nombre de la pintura y la frase "Museo Nacional". Acompañan a esta escena tres más con representaciones alusivas a la travesía de Cristóbal Colón cada una con las siguientes frases "Embarque de Colón en el Puerto de Palos"; "Cristóbal Colón aplaca la rebelión” y "Toma de Posesión de la Primera Tierra del Nuevo Mundo".

El complejo discurso visual de la pieza propició las interrogantes que recorren este ensayo $^{3}$ : ¿Por qué una pintura académica que representa un discurso hispanista, decimonónico y hegemónico es apropiado por un universo indígena, quechua hablante e iletrado? ¿Cuál es su significado? y ¿Cómo se inserta esta obra en el museo y qué nos dice esta pieza sobre esta institución?

\section{Los funerales de Atahualpa, una ficción fundacional}

Es evidente el rol paradigmático de la obra Los Funerales de Atahualpa (1861-1867) de Luis Montero en la pintura histórica decimonónica peruana y americana (ver página 18). La poderosa imagen es para la historiografia del arte, en palabras de Sommer (2004), una ficción fundacional que construye arquetipos modelizadores sobre los que las burguesías criollas de las nacientes repúblicas afianzan su hegemonía a través de

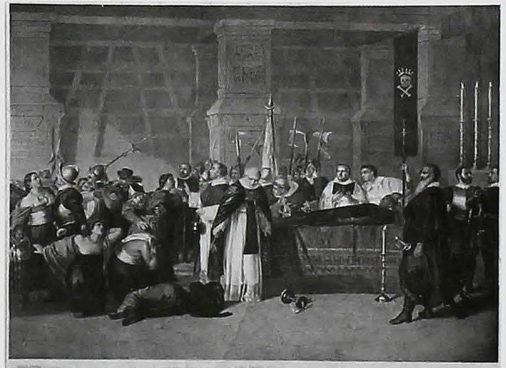

F. Siber, grabador; George Brunswig, editor. Los funerales de Atahualpa, ca. 1871 1872. Litografia sobre papel, 60.5 x $45.5 \mathrm{~cm}$. Colección Museo de Arte de Lima, Donación anónima.

3 Esta idea surgió el año 2006, en el proceso de curaduría de la muestra El fruto decorado, Mates burilados del valle del Mantaro, realizado con la historiadora de arte Kelly Carpio Ochoa, bajo los auspicios de la Universidad Ricardo Palma y el ICPNA. Este ensayo recoge sus valiosas contribuciones al estudio de este género artístico y al estudio de Mariano Inés Flores. 
relatos sobre los que descansa su poder y repiten la mirada colonialista. La obra que desborda significaciones, refleja el ambiguo proyecto político de una burguesía nacional emergente que buscó fundar sus bases en el triunfo de lo español sobre lo indígena (Miró Quesada [1983] (2011) y el eje de un indigenismo impreciso y de cierto anti-hispanismo de salón, un tópico del incaísmo ilustrado con el que el nacionalismo peruano de la época sintonizó (Majluf 2011: 64).

Desconocemos la procedencia de la serie dedicada a Cristóbal Colón que complementa la pieza pero la naturaleza del dibujo alude a alguna de las diversas series de grabados europeos del siglo XIX que ilustraban la vida del viajero. Colón fue popular en la iconografía italiana y española desde fines del s. XVI, pero en el siglo XIX su imagen alcanzó el mayor auge y fue largamente celebrado en óperas, ballet y piezas de teatro. Aunque su papel en la iconografía oficial ha sido ambiguo, las escenas que aparecen en el mate refieren al exitoso viaje y el arribo de Colón a tierras americanas.

\section{El azucarero Los funerales de Atahualpa}

El azucarero de Los funerales de Atahualpa cita una obra sumamente compleja en su composición y simbolismo que contrasta con la naturaleza modesta del materia. La pericia técnica del burilador controla adecuadamente la distribución de los personajes, cuya composición es resuelta optando por mostrarlos de perfil o de frente. Versátil en el manejo de la línea y la incisión, el artista ha captado la disposición y características del Atahualpa yacente, el Padre Valverde, Francisco Pizarro, las mujeres y el cortejo español, plasmando posturas, gestos y ropajes.

La amplia circulación y reproducción que tuvo la obra de Montero en diversos medios y soportes a nivel regional e internacional hacen casi imposible detectar con precisión si el burilador alcanzó a ver la obra original o cuál fue el referente que utilizó. Sin embargo, por la forma simplificada de los vanos de las hornacinas trapezoidales del muro inca simplificadas en líneas diagonales y horizontales como se observa en el mate, se puede vincular con la litografia de George Brunswig (1872), retomada en la copia que hizo el pintor José Effio en 1910 y publicada en la revista Mundial en 1920 (Majluf. 2011).

Las tres imágenes de Cristóbal Colón siguen el mismo patrón. Se trata de escenas en las que se observa al viajero genovés rodeado de su comitiva de marinos, autoridades eclesiásticas, galeones y carabelas. Cabe destacar que en las escenas el indígena americano, también protagonista de este encuentro, está ausente; paradójicamente se muestra un "encuentro sin conflictos o a lo sumo de simple superioridad colonialista, en principio ajeno a la nueva identidad nacional española que pretendía construirse". (Reyero 2004:722)

Pese al origen occidental de la iconografía de Colón, en el mate el artista utiliza una estrategia compositiva distintiva de los mates de esa región y que se evidencian en las piezas 




Escena Toma de posesión de la primera tierra del Nuevo Mundo. Colección Museo Nacional de la Cultura Peruana.

del siglo XIX: la de completar los vacíos con flores y hojas en un tupido follaje que inunda los espacios del fruto en característico horror vacui.

Por el trazo de las imágenes, las tapas con lacerías mudéjar y el follaje frondoso del azucarero, la pieza ha sido atribuida a Mariano Flores (Acevedo 1999 y Carpio 2006). Flores nacido en el distrito de Mayoc, Churcampa Huancavelica, fue identificado en 1932 por José Sabogal y reconocido como el más diestro artífice de este género ${ }^{4}$. Es poca la información que se tiene sobre Flores, se sabe que fue un campesino iletrado que pasó sus últimos años en el olvido (Quijada 1985).

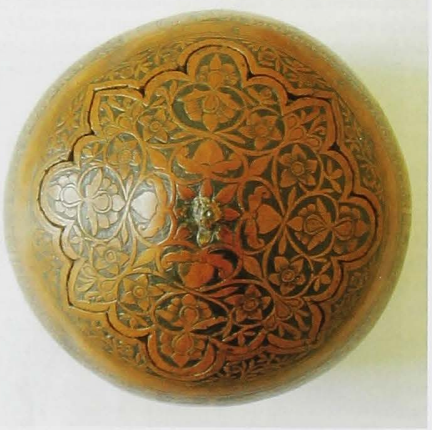

Parte superior del mate Los funerales de Atahualpa. Colección Museo Nacional de la Cultura Peruana.

4 Para Sabogal el mate es -hijo mestizo de dos culturas que se unían "sin complicarse", la sintesis armoniosa de dos tradiciones (Sabogal 1929), tópico que se convertirá en el derrotero de su obra plástica y literaria. No obstante, el pintor cajamarquino no duda en resaltar el carácter hispano de los temas y los elementos decorativos, producto de un proceso "plástico-criollo". 


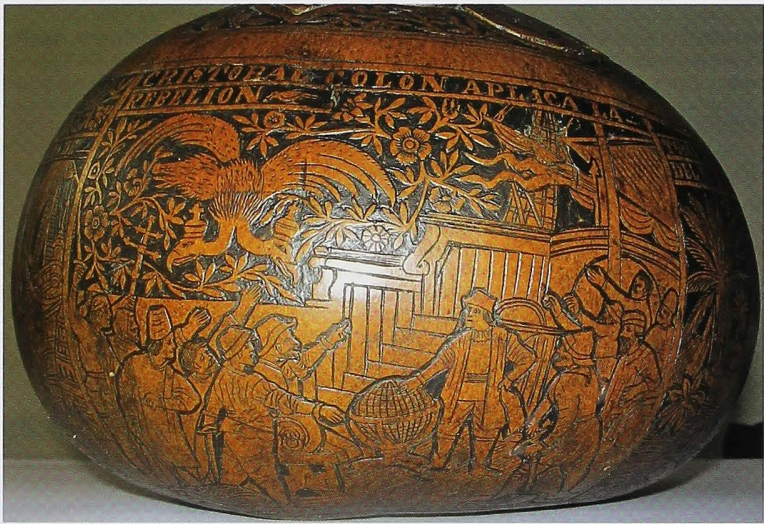

Escena Cristóbal Colón aploca la rebelión. Colección Museo Nacional de la Cultura Peruana.

\section{Una iconografía extraña}

En la escena en la que se presenta la obra "Cristóbal Colón aplaca la rebelión" se aprecia un elemento iconográfico insólito en el lado superior derecho ¿un cóndor bicéfalo?, ¿acaso el artista habría representado el escudo de los Habsburgo en clave andina? La imagen rompe con todo el simbolismo del conjunto y sugiere un lenguaje sin antecedentes con una estética diferente al resto. El águila bicéfala fue un código resignificado por la aristocracia surandina para simbolizar su estirpe noble. Esta imagen nos permite arriesgar dos hipótesis. La primera es que a través del cóndor el "señor" o criollo que encargó la pieza buscó representar a su grupo social y la segunda es que se trata de una licencia del artífice o "indio" con la que presentaba su propia tradición cultural, a través de una entidad vigente el universo oral narrativo como se observa en los sanmarkos ayacuchanos y otros objetos simbólicos del mundo rural andino.

A diferencia de la extendida fama y difusión que tuvo Luis Montero, la identidad de Flores está llena de enigmas, omisiones y olvidos (Yllia 2006), que además de ser correlato del carácter subalterno de su creador, revela los conflictos y complejidades que ha perseguido la utopía del mestizaje como elemento unificador del arte peruano contemporáneo planteado por el discurso indigenista y materializado en el llamado arte popular, conceptos avalados desde el Instituto de Arte Peruano por José Sabogal (Villegas 2006) y desde el Museo Nacional por Luis E. Valcárcel.

El mestizaje que Flores representaba para Sabogal estaba expresado en los saberes de la vida del campo -en los que se traducía un conocimiento milenario-y a su vínculo indesligable con el paisaje a los que se sumaba la impronta virreinal, temas que confluían en los mates: corridas de toros, bautizos, matrimonios, carnavales, fiestas patrióticas, herranzas, trillas, entre otras propias de la vida campesina. El uso del término mestizo en vez de indio utilizado por Sabogal era reflejo de los prejuicios raciales de la intelectualidad provinciana 
característica de la época. Se trata de un tópico presente en los discursos de las primeras décadas del siglo XX, cuando las "taxonomías étnicas funcionaron para distinguir a los indios -putativos descendientes contemporáneos de las originales civilizaciones precoloniales- de los mestizos- antiguos indios, si bien tampoco blancos" (De la Cadena 2004:45). La desindianización del burilador, convertido en mestizo, significaba otorgarle un estatus superior, pues era reconocido como "un artista". Esto, al mismo tiempo, dejaba ver la distancia y desconocimiento que existía de los complejos sistemas de producción estética de las sociedades andinas, ya que no conciliaban con la lógica del arte occidental europeo.

El pintor indigenista las concibió como escenas "libremente ejecutadas por los artistas", sublimando a sus creadores y otorgándoles un halo de incorruptibilidad y pureza. El esencialismo de Sabogal lo llevó a rechazar otro tipo de repertorios afirmando que "también se vio forzado a grabar cosas que no entendía cuando copiaba modelos obligado por los señores cultos ... desde una "Respuesta de Bolognesi" a escenas truculentas de las oleografias de "Traviata" y el "Barbero de Sevilla, que "artísticamente no son genuinos, sino provenientes de la copia de estampas" (Sabogal, 1989: 253). Lo genuino del arte mestizo excluía los repertorios académicos e históricos que no daban cuenta de la vida y realidad del hombre contemporáneo, tal como era concebida e inventada.

Esta idea planteada repetidamente en los escritos del pintor cajamarquino nos lleva a presumir que la pieza no fue objeto de su interés ni del programa de investigación del Instituto de Arte Peruano 5 . Si Sabogal no fue el autor intelectual del discurso narrativo que exhibe ¿quién pudo haberlo hecho?

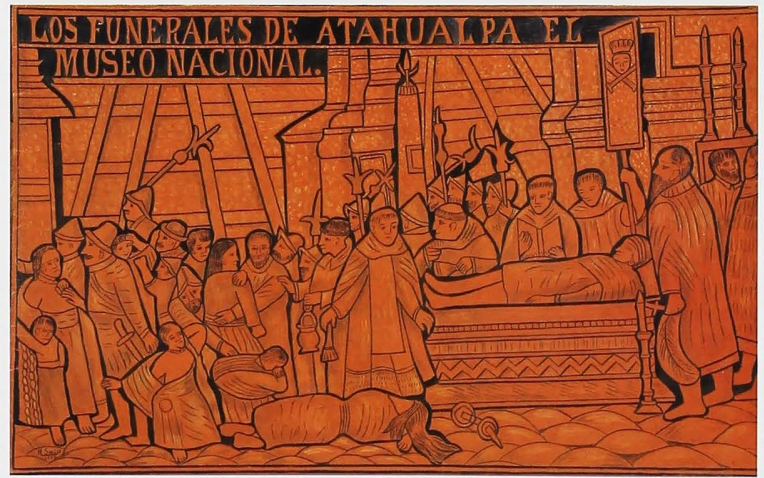

Rosa Saco. Los funerales de Atahualpa. Témpera, 1975. Colección Museo Nacional de la Cultura Peruana.

La diferencia del discurso visual del mate respecto a otros encargados por miembros de la élite mestiza huantina -que aluden a temas regionales como la Punición Parra u otros vinculados a la Guerra con Chile (Macera 1980, Carpio 2006), nos enfrenta a la idea de que fue encargado por un miembro de la ciudad letrada. Es desde esta perspectiva que el discurso

5 Si bien existe una pintura que reproduce la pieza, ésta fue realizada en la década de 1970. 
visual del mate se convierte en una etnoficción del discurso colonialista "la fabricación de un discurso étnico artificial destinado exclusivamente a un público ajeno a la cultura exótica" (Liendhard 1990:290). La aparición de la cita "Museo Nacional" debajo de "Los Funerales de Atahualpa", vincula directamente al mate con su discurso oficial legitimador y a los intelectuales que estaban detrás de él.

\section{El mate Los funerales de Atahualpa, Luis E. Valcárcel y el Museo Nacional}

Un dato de trascendental importancia en el estudio de este mate es su aparición en el Inventario de la colección arqueológica enviada a la exposición internacional de París en 1937. El documento firmado por Luis E. Valcárcel y Juan José Delgado, lleva el sello del departamento de Antropología de Museo Nacional ${ }^{6}$. Se trata de la primera mención oficial de la pieza en los archivos del museo.

La exposición Internacional de París "Artes y técnicas de la vida moderna" de 1937 alcanzó gran éxito a nivel internacional pese a la tensa situación política de Europa antes de la Segunda Guerra Mundial. Se trató de una de las más célebres presentaciones del arte peruano en el extranjero, luego de la exposición del Pabellón Peruano de la Exposición Iberoamericana en Sevilla, España en 1929. En ambas el país buscó diversas estrategias y referentes para representarse a sí mismo como nación moderna ante el mundo y obligó a la esfera política a definir lo peruano.

En el escenario parisino, el Perú había tenido protagonismo a través de la imponente exposición de piezas arqueológicas que se exhibió en el Museo Louvre (1928) y a la difusión y el alcance que tuvo el trabajo realizado por las hermanas Elena y Victoria Izcue, que lograron articular los encandiladores diseños precoloniales a la élite parisina a través de su aplicación decorativa en objetos suntuarios. Debido a ello, no fue extraño que Elena Izcue recibiera el encargo del Ministerio de Fomento de decorar parte del Pabellón Peruano con diseños precoloniales (Majluf y Wuffarden 2009).

El discurso que sustentó la selección que preparó Valcárcel tuvo la siguiente premisa:

"El Perú tiene una doble herencia artística. Las antiguas culturas aborígenes dejaron testimonios muy valiosos en arquitectura, textilería, cerámica, metalistería. Los conquistadores españoles posesionados de la tierra, trasplantaron junto con los productos de las economías nuevas para América, como el trigo y la vid, las artes pictórica, escultórica y arquitectónica de los siglos renacentistas. Las dos inspiraciones confluyeron, ésta ostensiblemente bajo la dirección de los maestros peninsulares, aquella forma subconsciente como réplica obstinada y profunda. El resultado fue una nueva creación artística que se puede comprobar en la mayoría de las obras salidas de manos indias o mestizas: templos de Puno, Arequipa y Cusco, alfombras, tapices, vasos de madera, mates, platería, cerámica pucareña, etc." 189-190.

Las piezas arqueológicas no fueron protagónicas en la exhibición de París, a pesar de su carácter e importancia sino que sirvieron para instrumentalizar un discurso que enfatizaba la continuidad cultural hasta la actualidad.

El azucarero de Los funerales de Atahualpa encarnaba la doble ecuación planteada por Valcárcel, era fruto de "manos indias o mestizas" y a través de él se advertía la "doble herencia artística". Al igual que la cerámica Moche, Nazca, Tiahuanaco e Inca se trataba de piezas anónimas con un "refinado gusto lindante con lo moderno" (Valcárcel: 186).

6 Inventario de la colección arqueológica enviada a la Exposición internacional de París, 1937. MN/ALEV. MN 016. 
No son abundantes las referencias de Luis E. Valcárcel al arte popular, su interés de crear un museo para este conjunto de piezas respondía más al programa sabogalino. Su verdadera pasión, que no fue desatendida en el Pabellón de París, era afirmar el sitial de Cusco como puputi u ombligo de la nación peruana, capital del Imperio de los Incas y ciudad más antigua de América, presentada en esa ocasión a través de grandes reproducciones fotográficas que ambientaban los espacios y daban cuenta de su sofisticada tecnología (Valcárcel 1937). Esa fue la línea planteada en la pintura de José Sabogal, Camilo Blas, Alejandro González y Francisco González Gamarra, artistas que representaban en ese ámbito el arte peruano "contemporáneo".

Los funerales de Atahualpa como tema, traduce visualmente "el primitivo duelo entre las dos herencias, la importación de elementos culturales (ideologías, lenguaje, oratoria, arte) de los mestizos y criollos" (Valcárcel 1937).

... un rumbo distinto es impreso por los mestizos y criollos que dirigen las campañas militares. Una nueva importación de elementos culturales: (ideologías, lenguaje, oratoria, arte) determina la persistencia del primitivo duelo entre las dos herencias. La indígena se reduce al arte popular en tanto que la española renueva sus aportes, tomándolas de otras fuentes europeas.(Valcárcel 1937:190).

Valcárcel presenta al arte popular como subalterno y concibe a sus artífices como colectivo. En ese sentido enfrenta la misma encrucijada que persiguió a Sabogal-ambos eran provincianos radicados en Lima-, la imperante necesidad de afirmar su propia identidad y distancia frente al "indio".

Paradójicamente, el discurso de Valcárcel no está muy alejado de la tesis del polígrafo José de la Riva Agüero que afirmaba que "El Perú moderno vive de dos patrimonios: del castellano y del incaico, el segundo aunque subalterno en ideas, instituciones y lengua es el primordial en sangre, instinto y tiempo. En él se contienen los timbres más brillantes de nuestro pasado" (Riva Agüero 1912). No podemos olvidar la relación que existió entre los dos intelectuales y la fugaz participación de Riva Agüero en el Museo Nacional.

Por otro lado el discurso de la pieza en mención es correlato del renacer hispánico que se dio en el ambiente intelectual limeño con la toma del Presidente Oscar R. Benavides (1936) y la dictadura autocrática militar y sus vínculos con el fascismo europeo y el régimen franquista, que una vez más mostraba nuestra fragmentada peruanidad (Molinari 2012).

Al amparo del Museo Nacional como institución, Valcárcel replanteó su lectura de la cultura peruana distante a su juvenil indigenismo cusqueñista colmado de excesos utópicos (Rénique 2013:46). Como señala Macera, "una vez en Lima Valcárcel procuró diseñar su propia función intelectual en términos modernos internacionales e institucionalizados" (Macera 2009 [1979]:108). Ya a cargo de los Museos Nacionales, afirmaba que "lo ideal sería construir el gran edificio único en que pudiéramos representar el maravilloso panorama de nuestra raza" (Valcárcel [1932] 2013:348), dejando ver los rezagos del positivismo social en su discurso y la necesidad de plantear una lectura totalizadora de la cultura peruana, entendida como un gran proceso, resultado del mestizaje cultural.

A través del Museo Nacional Valcárcel conoció otras formas de mirar al Perú, como la planteada por José Sabogal y otros artistas e intelectuales con los que dialogó, atemperó sus angustias y ganó tolerancia frente a lo hispánico. La atención hacia el presente no era ajena a su mirada, quien en una carta escrita al español Juan Larrea en $1935^{7}$, en la que alude lo indio, lo cholo, los colonialismos y la complejidad de definir lo peruano, señala que en esta situación, "los arqueólogos tenían que vérselas también con los vivos".

7 Correspondencia con Juan Larrea, 1935. MN/ALEV. 
Como la historia no deja de ser antojadiza, la ficción fundacional que Luis Montero pintó para ser exhibida originalmente en la Exposición Universal de París de 1867 llegó a la misma ciudad setenta años después, convertida en una etnoficción, realizada desde el mundo indígena, rural e iletrado y utilizado desde el ámbito oficial para representar la bidimensionalidad de la cultura peruana. La ideología indigenista una vez más repetía el discurso criollo decimonónico, y proponía encontrar en la idea utópica y homogenizadora del mestizaje la respuesta a un problema sumamente complejo.

Resulta paradójico que el mate burilado de Huancavelica, el primero que entró al Museo Nacional y que tuvo contacto con élites ilustradas de la capital, sea precisamente un género que se extinguió, migró y se reinventó en otro espacio social en Huancayo. Al ingresar al museo la pieza se fosilizó, dejó de cumplir su ciclo y quedó en el olvido, al igual que su creador, celebrado y reconocido tan solo falazmente ${ }^{8}$.

8 Una versión preliminar de este ensayo fue presentada en el simposio "Escritura e imagen en Hispanoamérica: De la crónica ilustrada al cómic", organizado por la maestría en Historia del Arte de la Pontifica Universidad Católica del Perú.

Agradezco a Soledad Mujica y Estela Miranda del Museo Nacional de la Cultura Peruana por haberme facilitado el acceso a la pieza. A Fernando Brugué Valcárcel por permitirme revisar su archivo. A Kelly Carpio. Fernando Villegas, Manuel Cornejo Chaparro y Sara Joffré por su atenta lectura e importantes sugerencias. 


\section{Referencias bibliográficas}

Acevedo, Sara

1999 Machu Iñis. Mariano Inés Flores burilador de mates de San Mateo-Huancavelica en el cincuentenario de su desaparición. Lima. Museo Nacional de la Cultura Peruana.

Anónimo

1920,17 de enero. Exposición de arte ayacuchano. Variedades, 620 (16).

1920, 24 de enero. Variedades, 621 (16).

Arguedas, José María

Notas elementales sobre el arte popular religioso y la cultura mestiza en Huamanga. Revista del Museo Nacional. XXVIII, 140-194.

1956, diciembre Sabogal y la Artes Populares en el Perú. Folklore Americano: 4 (4), 241-245.

Carpio, Kelly

2006 El fruto decorado. Mates burilados del Valle del Mantaro, una aproximación a su origen En El fruto decorado. Mates burilados del Valle del Mantaro (siglos XVIII$X X)$ (21-41). Lima: URP-ICPNA.

De la Cadena, Marisol

2004 Indígenas mestizos: raza y cultura en el Cusco. Lima: IEP.

Jiménez Borja, Arturo y H. Colán

1943 Mates peruanos. Revista del Museo Nacional. Lima, Vol. XIII, 2935.

Lauer, Mirko

1976 Introducción a la pintura peruana del s. XX. Lima: Mosca Azul.

1991 Minka, un salto en la plástica Andina. Nueva Sociedad $N^{\circ} .116$ noviembrediciembre, pp. 130-136

Liendhard, Martin

1990 La voz $y$ su huella. Escritura y conflicto étnico social en América Latina (14921988). Ensayo. Premio Casa de las Américas.

1990 La voz y su huella. Escritura y conflicto étnico-social en América Latina (1492. 1988). La Habana: Casa de las Américas.

Macera, Pablo

1979 Pintores populares andinos. Lima. Fondo del libro del Banco de los Andes.

1980 "El arte popular y la guerra con Chile". El Comercio. Suplemento Dominical. Lima, 8 de junio, pp.14 15.

Majluf, Natalia

2011 Lima Santiago y la posteridad. En Majluf, N. (Ed.), Luis Montero. Los funerales de Atahualpa (152-172).Lima: MALI.
2011 Pintura, historia y verdad: Los funerales de Atahualpa de Luis Montero. En Majluf, N. (Ed.), Luis Montero. Los funerales de Atahualpa (54-86).Lima: MALI,

Majluf, Natalia y Luis Eduardo Wufarden Elene Izcue. El arte precolombino en la vida moderna.

2013 Sabogal. Lima: MALI, BCP.

Miró Quesada, Roberto Los funerales de Atahualpa. En Majluf, N. (Ed.), Luis Montero. Los funerales de Atahualpa (48-).Lima: MALI.

Molinari, Tirso

2012 Dictadura, Cultura Autoritaria y Conflicto Político en el Perú. 1936-1939. Tesis para optar el grado Académico de Doctor en Ciencias Sociales con especialidad en Historia. UNMSM.

Pinto, Miguel

2009 Trincheras y fronteras del arte popular peruano. Ensayos de Pablo Macera. Lima: Fondo Editorial del Congreso de la República.

Quijada Jara, Sergio

1985 El artífice de los mates burilados. En Estampas Huancavelicanas. Lima 2da edición. Edugrafics S.R.L, 1985.

Renique, José Luis

2013 Encuentro con un fundador. En. Luis E. Valcárcel: Del indigenismo cusqueño a la antropología peruana. Tomo I. Lima: Ediciones Copé-Petroperú, Fondo Editorial del Congreso del Perú, Instituto de Estudios Peruanos. p. 15-81

Reyero, Carlos

2004 Pasivos, exóticos, vencidos, víctimas. El indígena Americano En La Cultura Oficial Española Del Siglo XIX. Revista de Indias. Vol. LXIV, núm. 232, p. 721-748.

Sabogal, José

1929 septiembre, octubre. Los 'mates' y el Yaraví. Amauta, 26, 17-20.

1929 "Los mates y el yaravî" Amauta $\mathrm{n}^{\circ} 26$, Lima octubre noviembre.

1932 marzo, abril. Mariano Flórez, artista burilador de 'mates' peruanos, murió en Huancayo: José Sabogal su admirador y amigo le rinde homenaje. Quipus, 4, 5, (2) , 10- 11 .

1932 "Mariano Florez, artista burilador de mates peruanos murió en Huancayo". Quipus, $n^{\circ} 4-5$. Lima, marzo-abril, pp. 10-11. 
1945 Mates burilados. Arte vernacular peruano. Buenos Aires: Editorial Nova, colección Mar Dulce.

1989 Obras literarias completas .Lima: Ignacio Prado Pastor (Ed.). Lima: CONCYTEC.

1989 Obras completas. Lima: Prado Pastor editor. CONCYTEC.

Sabogal Wiesse, José

1975 Cinco ensayos sobre artesanía, arte popular, artesanos en el Perú. Lima: SINAMOS.

\section{Sommer, Doris}

2004 Ficciones fundacionales. Las novelas nacionales de América Latina. Bogotá: Fondo de Cultura Económica.

Stastny, Francisco

1981 El arte popular peruano. Lima:Edubanco.

Valcárcel, Luis E.

1937 El Museo Nacional y la Exposición de París. Revista del Museo Nacional, 6 (2), 184-200.

1937 "El Museo Nacional y la Exposición de París". Revista del Museo Nacional, T. VI, $\mathrm{n}^{\circ} 2$, II semestre 1937. P 184-200.

1950-1951. El Museo de la Cultura Peruana. Revista del Museo Nacional, 19 (20) 3 -6.

1956 José Sabogal. Revista del Museo Nacional, (25), 28-29.

1981 Memorias. Matos Mar, J.; Deustua J. \& J.L. Rénique (edit.). Lima: IEP.

2013 Luis E. Valcárcel: Del indigenismo cusqueño a la antropología peruana. Tomo I. Lima: Ediciones Copé-Petroperú, Fondo Editorial del Congreso del Perú, Instituto de Estudios Peruanos
Villegas, Fernando

2006 El Instituto de Arte Peruano (1931-1973): José Sabogal y el mestizaje en el arte. lllapa. 3(3), 21-44.

2008 José Sabogal y el arte mestizo. El Instituto de Arte Peruano y sus acuarelas. Lima: 2008. Tesis de Licenciatura E.A.P. Arte. Universidad Nacional Mayor de San Marcos.

Wiesse, María

1957 José Sabogal el artista y el hombre. Lima: Compañía de impresiones y publicidad.

Wuffarden, Luis Eduardo

2004 Julia Codesido, entre el indigenismo y el espíritu de la modernidad. Lima: Pontificia Universidad Católica del Perú.

Yllia, María Eugenia

2006 El mate mestizo de José Sabogal. En El fruto decorado. Mates burilados del Valle del Mantaro (siglos XVIII-XX) (45-55). Lima: URP-ICPNA 
